\title{
Medical emergencies in dental offices in Slovenia and readiness of dentists to handle them
}

\author{
NEJC UMEK ${ }^{1}$, MAJA ŠOŠTARIČ $\check{C}^{1,2}$ \\ ${ }^{1}$ Department of Anaesthesiology and Reanimatology, University of Ljubljana, Faculty of Medicine, Slovenia \\ ${ }^{2}$ Clinical Department of Anaesthesiology and Intensive Therapy, University Medical Centre Ljubljana, Slovenia
}

Corresponding author:

Maja Šoštarič

University Medical Centre Ljubljana

Zaloška cesta 7, 1000 Ljubljana

Phone: 0038615223143

E-mail:maja.sostaric@kclj.si

\section{ABSTRACT}

Introduction. Dentists, and all other dental healthcare workers, can expect to face a medical emergency directly or indirectly related to dental treatment. This study evaluates the incidence of medical emergencies in dental offices in Slovenia, the readiness of dentists and possession of specific medical equipment.

Methods. An anonymous online based questionnaire was sent through the Medical Chamber of Slovenia via email to all 1503 active dentists in Slovenia. The questionnaire was pilot-tested on 25 dentists and improved accordingly. Thirty closedended questions were answered by 289 (19.2\%) dentists.

Results. $93.4 \%(n=267)$ of dentists reported a medical emergency in their dental office. The most prevalent diagnosis was syncope (1.88-2.44/dentist/year) followed by hypoglycaemia (0.20-0.25/dentist/year), hypertensive crisis (0.4/dentists/year) and anaphylaxis (0.3/dentists/year). There were no cardiac arrests reported in the dentists' entire careers. $85.1 \%(\mathrm{n}=239)$ of dentists underwent postgraduate BLS training, $87.4 \%(n=209)$ of them in the last 5 years. Responding dentists estimated that they are most capable of dealing with syncope and least proficient in dealing with stroke, cardiac arrest and a hypertensive crisis. They felt generally more prepared to manage than diagnose a medical emergency. Only $58.1 \%(n=161)$ of dentists have access to a self-inflating bag with a reservoir, and $54.9 \%(\mathrm{n}=152)$ to an oxygen mask. Only $4.0 \%(n=11)$ of them have a full set of equipment recommended by Medical Chamber of Slovenia.

Conclusions. Results support modification of the undergraduate and postgraduate curriculum for dental students to address specific medical emergencies and the usage of limited equipment. They support more rigorous regulations concerning postgraduate education and specific equipment for dealing with medical emergencies in dental offices in Slovenia.

Key words: emergencies, dental office, equipment, curriculum

\section{INTRODUCTION}

Dentists, and all other dental healthcare workers, can expect to face a medical emergency, directly or indirectly related to dental treatment. In the developed world, life expectancy is rising, and consequently, dentists are increasingly confronted with an older population with peculiar predispositions, such as a high burden of chronic diseases, greater need and intake of medications and an increased risk of drug interactions and adverse effects. (1) In addition, dental procedures themselves, which commonly involve the use of local anaesthetics, delicate surgical processes, as well as intense patient anxiety, can increase the chances of medical emergencies. (2)

The most commonly reported medical emergencies in dental practice include vasovagal syncope, hypoglycaemia, angina, convulsions, asthmatic attack and anaphylactic reaction. Myocardial infarction and sudden cardiac death are fortunately very rare. (3) Earlier reports noted that medical emergencies in dental practice were relatively rare, with an average of one emergency per 3-4 years. (4) However, subsequent research in Europe revealed that $57 \%$ of dentists faced at least 3 medical emergencies per year and $36 \%$ of dentists reported more than 10 emergencies during the previous year. (5)

Accordingly, dentists are expected to possess both the requisite core competencies and adequate equipment capacity to di- agnose and appropriately intervene and manage potentially life-threatening medical emergencies that may commonly arise in their practice. Unfortunately, however, Girdler showed that only $12.9 \%$ of dentists consider themselves competent to make the correct diagnosis of a medical emergency, and more than $50 \%$ of UK dentists do not provide appropriate treatment when a medical emergency occurs. (6) As part of the curricular reform for undergraduate medical education in Slovenia, dental students are required to take part in two mandatory 60-hour long Emergency Medical Care training courses with their fellow medical students and a 30-hour course in Geriatric Dentistry, where they learn specific medical emergencies they may face during dental practice. (7) After that, no formal education in emergency medical care is legally required during dentist's postgraduate education in Slovenia.

In addition to diagnostic and therapeutic capacities in medical emergencies, preventive strategies during dental treatment are equally imperative. Primary prevention can be achieved by carefully and comprehensively obtaining and updating patient medical histories, with emphasis on known allergies, adverse reactions to medications, chronic illnesses and chronic therapy, and accordingly observing precautionary actions with respect to findings. (8)

The aims of this study were to assess the incidence of medical emergencies in dental offices in Slovenia; to determine the confidence perception of dentists in Slovenia with regard to dealing with medical emergencies; to evaluate whether dental offices are properly equipped for adequately responding to medical emergencies; and to ascertain whether dentists are participating in postgraduate courses in emergency medical care and if this reflects on their self-confidence. 


\section{METHODS}

An online questionnaire developed with the online tool Survey Monkey (SurveyMonkey Inc, Palo Alto, California, USA) was distributed via email to all 1503 active dentists registered with the Medical Chamber of Slovenia. The survey was preliminarily approved by Republic of Slovenia National Medical Ethics Committee (108/07/14) and was conducted in March 2015, in full accordance with the World Medical Association Declaration of Helsinki. The survey questionnaire contained 30 closed questions divided into six sections:

1. Demographic background including nature of practice. Dentists were asked about their area of specialisation (orthodontics, periodontology etc.); the ownership and structure of their practice (private or government owned, separate or part of a dispensary); the location of their practice (rural or urban); and the relative proportion of paediatric and adult patients.

2. Number of medical emergencies encountered in the last 12 months and the total number of such emergencies managed in a life-time of dental practice. Ten categories of medical emergencies were evaluated: syncope, anaphylaxis, asthma, airway obstruction, seizure, hypoglycaemia, hypertensive crisis, acute coronary syndrome, cardiac arrest, stroke and other forms of emergencies that do not fit into the listed categories.

3. Emergency training experience. Dentists were asked about their frequency of participation in BLS (basic life support) courses, the interval since the last course, and their knowledge of the use of AED (automatic external defibrillators).

4. Self-perception of competencies in recognising and managing medical emergencies. To estimate their emergency response proficiency, dentists were asked whether they are able to perform specific basic skills correctly (BLS algorithm, establishing intravenous access, chest compressions) using a 6-point Likert scale from 1 ("completely disagree") to 6 ("completely agree"). We also evaluated whether dentists agree with the following statements: "I am able to diagnose my patient with the following medical emergency..." and "I am able to treat my patient with the following medical emergency ...."

5. Basic emergency equipment in individual dental practices. Availability of the following equipment was assessed: oxygen cylinder, bag valve mask with reservoir, pocket mask, oropharyngeal airway, oxygen mask, and oxygen mask with reservoir, portable suction, syringes and needles, spacer, blood pressure monitor, blood glucose meter, AED.

6. Practice and competency in obtaining and recording a medical history about general health, allergies and regular medical therapy.

The questionnaire was pilot-tested on 25 dentists before the study, to evaluate the relevance of questions, response format and phrasing. Inclusion criterion was: fully completed sections on demographic data and incidence of medical emergencies. The questionnaire was anonymous which did not allow us to identify and track responders and non-responders. Demographic data about the population of dentists in Slovenia was obtained from Medical Chamber of Slovenia and was used to evaluate the representativeness of the sample.

\section{STATISTICAL ANALYSIS}

The data obtained were systematically collected and missing data noted. For descriptive analysis of variables, as well as calculating significant differences, SPSS v.12.0 for Windows (SPSS inc., Chicago, Illinois, USA) was used. The Shapiro-Wilk test was used to evaluate the data of groups for Gaussian distribution, while the MannWhitney U test or Kruskal-Wallis test was used to assess for differences between groups for data which were not normally distributed. Representativeness of the sample was evaluated using Chi-Square test. A statistically significant difference was determined at $\mathrm{P}=0.05$.

\section{RESULTS}

\section{Demographic data}

A total of 332 questionnaires were returned. Of these, 43 did not meet the inclusion criteria and were consequently excluded from the analysis. Hence, a total of 289 questionnaires were analysed, representing $19.2 \%$ of all 1503 active dentists in Slovenia. The average age of the responding dentists and all active dentists in Slovenia was $42.8( \pm$ SD 9.72) and 46.4 $( \pm S D$ 11.91) years, respectively. Most of the participating dentists have had long careers: $10.7 \%(n=31)$ had been practicing for more than 30 years, $23.9 \%(n=69)$ for $20-29$ years, $30.8 \%(n=89)$ for $10-19$ years and $34.6 \%(n=100)$ for less than 10 years. They were distributed proportionally among all Slovenian health regions. Demographic data are shown in Table 1. Statistically significant differences were found between participating dentists and the whole population of active dentists in terms of gender, practice ownership and specialisation distribution, indicating that representativeness of the study sample may not be optimal.

\section{Incidence of medical emergencies}

Most of the respondents $(93.4 \%, \mathrm{n}=267)$ indicated that they had faced medical emergency situations in their dental practice. Of these, $67.5 \%(n=195)$ reported at least one medical emergency during the previous twelve months, while 39.8 $\%(n=115)$ recorded up to three medical emergencies and $26.3 \%(n=76)$ from three to ten medical emergencies, in the preceding twelve months. The most commonly reported medical emergency was syncope. No cardiac arrest was reported in the previous twelve months or over the entire career span, but there were 16 potentially life-threatening events (anaphylaxis, airway obstruction, acute coronary syndrome and stroke) reported in the antecedent twelve months. The incidence of medical emergencies is featured in Table 2.

\section{BLS training}

Of the 281 dentists that responded to this section, $94.3 \%(n=265)$ acknowledged receiving BLS training during their undergraduate medical education. After graduation, $85.1 \%(n=239)$ of the responding dentists reported undergoing BLS training: $87.4 \%(n=209)$ of them within the preceding 5 years and $12.6 \%(n=30)$ more than 5 years before. Most dentists $(74.3 \%, \mathrm{n}=209)$ were also trained on how to use AED. Forty-two of the responding dentists (14.9\%) had however never taken part in any BLS training after graduation. Only $45.2 \%$ $(n=127)$ of responding dentists reported receiving training in establishing peripheral venous access.

Self-estimation of competence in diagnosis and management of medical emergencies Responding dentists estimated that they are most capable of diagnosing and managing syncope and least proficient in diagnosing and managing stroke, cardiac arrest and a hypertensive crisis. Excluding syncope, hypertensive crisis, hypoglycaemia and acute coronary syndrome, dentists estimated that they are generally more prepared to manage than diagnose medical emergencies. The degree of agreement with each statement is depicted in Table 3. Den- 
Table 1. Demographic data (nsample=289, npopulation=1503); Chi-Square test, ${ }^{\star} P<0.05$.

\begin{tabular}{|c|c|c|c|c|}
\hline & Sample & & Popul & \\
\hline & $\mathrm{n}$ & $\%$ & $\mathrm{n}$ & $\%$ \\
\hline \multicolumn{5}{|l|}{ Gender ${ }^{\star}$} \\
\hline Male & 78 & 27.0 & 549 & 36.5 \\
\hline Female & 211 & 73.0 & 954 & 63.5 \\
\hline \multicolumn{5}{|l|}{ Practice ownership $^{*}$} \\
\hline Government owned & 146 & 50.5 & 664 & 44.2 \\
\hline Private & 143 & 49.5 & 839 & 55.8 \\
\hline \multicolumn{5}{|l|}{ Specialisation $^{*}$} \\
\hline Without & 260 & 90.0 & 1285 & 85.5 \\
\hline Specialists & 29 & 10.0 & 218 & 14.5 \\
\hline \multicolumn{5}{|l|}{ Predominantly treating } \\
\hline Children & 85 & 29.4 & & \\
\hline Adults & 204 & 70.6 & & \\
\hline \multicolumn{5}{|l|}{ Location of practice } \\
\hline Independent & 139 & 48.1 & & \\
\hline Part of dispensary & 147 & 50.9 & & \\
\hline Hospital & 3 & 1.0 & & \\
\hline
\end{tabular}

Table 2. Incidence of medical emergencies $(n=289)$.

\begin{tabular}{|c|c|c|c|c|}
\hline \multirow[b]{2}{*}{ Emergency } & \multicolumn{3}{|c|}{ During a Twelve-Month Period } & \multirow{2}{*}{$\begin{array}{l}\text { Over Entire Career } \\
\text { Dentists Reporting } \\
\text { Emergency n (\%) }\end{array}$} \\
\hline & $\begin{array}{l}\text { Dentists Reporting } \\
\text { Emergency n (\%) }\end{array}$ & Number of Cases Reported & Case/Dentist/Year & \\
\hline Syncope & $179(61.9)$ & 543-705 & $1.88-2.44$ & $248(82.8)$ \\
\hline Hypoglycaemia & $28(9.7)$ & $59-73$ & $0.20-0.25$ & $87(30.1)$ \\
\hline Anaphylaxis & $9(3.1)$ & 9 & 0.03 & $28(9.7)$ \\
\hline Hypertensive crisis & $8(2.8)$ & 12 & 0.04 & $25(8.7)$ \\
\hline Seizure & $6(2.1)$ & 6 & 0.02 & $74(25.6)$ \\
\hline Airway obstruction & $4(1.4)$ & 4 & 0.01 & $23(8.0)$ \\
\hline Asthma & $3(1.0)$ & 4 & 0.01 & $12(4.2)$ \\
\hline Acute coronary syndrome & $2(0.7)$ & 2 & 0.007 & $14(4.8)$ \\
\hline Stroke & $1(0.4)$ & 1 & 0.003 & $5(1.7)$ \\
\hline Cardiac arrest & $0(0.0)$ & 0 & 0.0 & $0(0.0)$ \\
\hline Other emergencies & $18(6.2)$ & 23 & 0.08 & $30(17.3)$ \\
\hline All emergencies & $195(67.5)$ & $663-839$ & $2,29-2,90$ & $270(93.4)$ \\
\hline Excluding syncope & $51(17.6)$ & $120-134$ & $0,42-0,46$ & $154(53.3)$ \\
\hline
\end{tabular}

tists that had undergone at least one postgraduate BLS training session, estimated that they are better prepared to diagnose, but not to manage, medical emergencies than dentists that had no postgraduate BLS training. Both could imply that procedural knowledge is better retained than declarative knowledge or that undergraduate and postgraduate curricula disproportionately emphasize proficiency in medical emergency treatment over competency in recognition/diagnosis. Responding dentists that had participated in postgraduate BLS training in the antecedent year estimated that they are better prepared to diagnose and treat some medical emergencies than dentists who had participated in postgraduate BLS training three to five years before, which may indicate that awareness of the depreciation of medical emergency management competence becomes significant in three to five years after BLS training. The degree of agreement with each statement is featured in Figures 1 and 2.
Out of 255 dentists that responded to this section, only $50.6 \%(n=129)$ completely or mainly agreed with the statement: "I am able to perform CPR (cardiopulmonary resuscitation) correctly and efficiently" and $60.4 \%(n=154)$ completely or mainly disagreed with the statement: "I am able to establish venous access".

\section{Equipment to manage medical emer- gencies}

Out of the 277 dentists that responded to 
Table 3. Estimation of competence $(n=255)$. Data shown represent a mean value; ${ }^{\star} P<0.05$ versus I am able to treat $($ Mann-Whitney $U$ test).

\begin{tabular}{|c|c|c|}
\hline Medical emergency & I am able to diagnose & I am able to treat \\
\hline Syncope & 5,3 & 5,3 \\
\hline Anaphylaxis & $4,1^{\star}$ & 4,8 \\
\hline Asthma & $3,6^{*}$ & 4,4 \\
\hline Airway obstruction & $4,8^{\star}$ & 5,1 \\
\hline Seizure & $4,6^{*}$ & 4,9 \\
\hline Hypoglycaemia & $4,8^{*}$ & 4,4 \\
\hline Hypertensive crisis & 3,7 & 3,9 \\
\hline Acute coronary syndrome & 4,1 & 4,3 \\
\hline Cardiac Arrest & $3,8^{\star}$ & 4,1 \\
\hline Stroke & $3,7^{\star}$ & 4,1 \\
\hline
\end{tabular}

Table 4. Practice of obtaining and recording a medical history $(n=277)$.

\begin{tabular}{|c|c|c|c|c|c|c|}
\hline & \multicolumn{2}{|c|}{ Taking a general medical history } & \multicolumn{2}{|c|}{ Taking a history about allergies } & \multicolumn{2}{|c|}{ Writing down the medical history } \\
\hline & $\mathrm{n}$ & $\%$ & $\mathrm{n}$ & $\%$ & $\mathrm{n}$ & $\%$ \\
\hline Never & 1 & 0.4 & 0 & 0 & 5 & 1.8 \\
\hline Only at first visit & 81 & 29.2 & 42 & 15.2 & 101 & 36.5 \\
\hline $\begin{array}{l}\text { Only before local } \\
\text { anaesthetic application }\end{array}$ & 28 & 10.1 & 58 & 20.9 & 6 & 2.2 \\
\hline Mostly & 95 & 34.3 & 97 & 35.0 & 60 & 21.6 \\
\hline Always & 72 & 26.0 & 80 & 28.9 & 105 & 37.9 \\
\hline
\end{tabular}

this section, only $54.9 \%(\mathrm{n}=152)$ had access to an oxygen mask in their dental office. Twenty-six percent $(n=72)$ of dentists also had access to an oxygen mask with a reservoir; $40.1 \%(n=111)$ had an oropharyngeal airway; $58.1 \%(\mathrm{n}=161)$ had a self-inflating bag with reservoir; $60.6 \%(n=168)$ had a pocket mask; $49.1 \%(\mathrm{n}=136)$ had an oxygen cylinder; $40.1 \%(n=111)$ had a blood pressure monitor; $43.0 \%(n=119)$ had a spacer device; $40.1 \%(n=111)$ had portable suction, while $93.1 \%(\mathrm{n}=258)$ had equipment for venous access. Only 11 dentists (4.0\%) had access to all these devices for managing medical emergencies as recommended by Medical Chamber of Slovenia. Additionally, $11.9 \%(n=33)$ of dentists had access to a blood glucose meter and $15.5 \%$ $(n=43)$ to an AED. Meanwhile, of the 234 dentists who do not have access to an AED in their dental office, 179 (76.5\%) of them claim to know where the nearest public access defibrillator (PAD) is placed.

\section{Practice of obtaining and recording a medical history}

Eighty-one (29.4\%) of 277 dentists that responded to this section, reported taking and writing down a general medical history only at the patient's first visit. The frequency of taking and writing down a medical history about general health issues and allergies is featured in Table 4. A weak positive correlation between dentist's age and frequency of general medical history taking was noted $(\rho=0.126, P=0.036)$.

\section{DISCUSSION}

The present study aimed primarily to determine the incidence of medical emergencies in dental offices in Slovenia. The preparedness of dentists in terms of selfconfidence to diagnose and manage medical emergencies, as well as the availability of basic medical equipment to manage medical emergencies were also evaluated. Being an anonymous questionnaire-based study conducted on the whole population of active dentists in Slovenia, the limitations of potential response and selection bias were taken into account. To minimise these, we designed a questionnaire with clear-cut closed-ended questions and ordinal answering scales. The questionnaire reached dentists of all ages from all Slovenian geographic health regions. Our sample consists of 289 respondents; thus our paper describes a sample of $19.2 \%$ of 1503
Slovenian dentist population at the time of study. Accordingly, we cannot assume that the returned questionnaires are representative of the whole active dentist population in Slovenia. Since the studied population as a whole is relatively small, the absolute number of responding dentists is lower than those of similar surveys conducted in other countries. $(5,6,9)$ To compensate for the low absolute number, we analysed all questionnaires that met the minimal inclusion criteria, unconstrained by considerations of sample representativeness.

Our results show that medical emergencies in dental practices are not infrequent. About two thirds of dentists faced at least one medical emergency during the previous twelve months, and the majority of them $(93.4 \%)$ had already experienced medical emergency situations in the course of their career. This clearly indicates that dentists should expect to be crucially involved in the diagnosis and management of medical emergencies. $(5,10)$ The most common of these emergencies was syncope, followed by hypoglycaemia, hypertensive crisis, anaphylaxis and seizures; however, in most cases the emergencies were not life-threatening. Our reported relative incidence of medical emergencies is gen- 


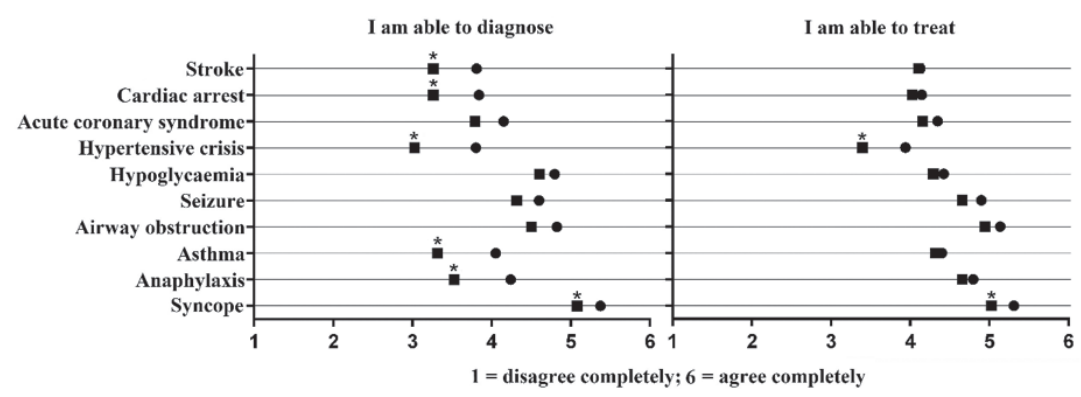

Figure 1. Estimation of competence for dentists who had never participated in BLS (basic life support) training before $(-)(n=38)$ and dentists who had already participated in BLS training at least once $(\bullet)(n=217)$. Data shown represent mean values; ${ }^{*} P<0.05$ versus dentists that had never participated in BLS training (Mann-Whitney U test).

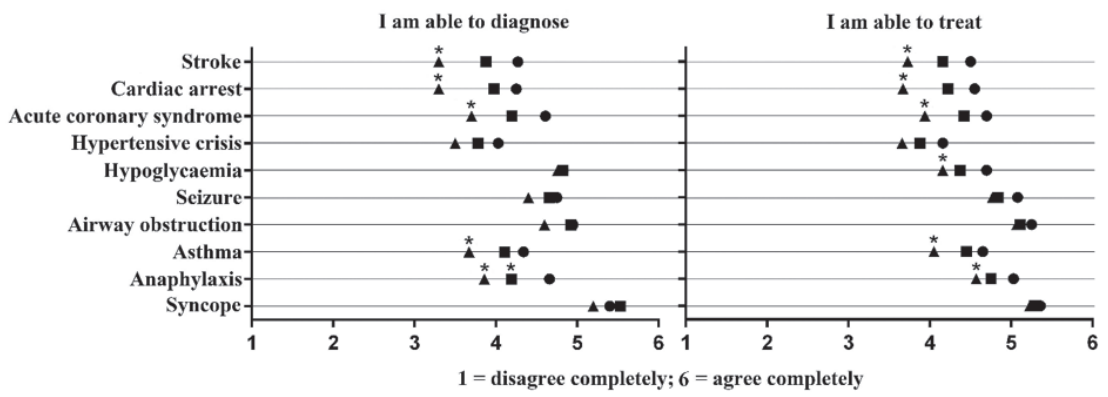

Figure 2. Estimation of competence for dentists that participated in their last BLS (basic life support) training less than 1 year ago $(\bullet)(n=59), 1-2$ years ago $(\bullet)(n=67)$, or 3-5 years ago $(\mathbf{\Delta})(n=60)$. Data shown represent mean values; ${ }^{*} P<0.5$ versus dentists that participated in their last BLS training less than 1 year ago (Kruskal-Wallis test).

erally congruent with previous studies $(3,5,9)$ and reemphasizes the urgency of a new professional consciousness of dentists regarding their expectation of and preparedness to effectively manage medical emergencies in their office. Based on our study, dentists can expect to face a medical emergency, other than syncope, every two to three years. Cardiac arrest was the medical emergency with the lowest incidence. No responding dentist encountered a cardiac arrest patient in their dental office over their entire career; paradoxically, this is the prime focus of BLS and ALS (advanced life support) training. Thus, it could be beneficial to modify the undergraduate and postgraduate curriculum for dental students to address these specific medical states and highlight the use of available equipment in dental offices.

The incidence of cardiac arrest in dental offices is very low and the cost effectiveness of AED in primary care is considered poor. (11) We estimate, that AED placement in
Self-estimation of therapeutic competences was generally better than self-estimation of diagnostic competences. Meanwhile, dentists who had undergone at least one postgraduate BLS/ALS training course estimated that they have better diagnostic competence than dentists who had not undergone any postgraduate training, but the same is not the case for self-estimation of therapeutic competences. Possible explanations could be that procedural knowledge is better retained than factual knowledge, or that BLS/ALS training courses in Slovenia are concentrating more on medical emergency treatment than recognition. However, this observation is not congruent with survey studies by Müller and Marks who showed that both diagnostic and therapeutic competences are better estimated by dentists who regularly participate in emergency training. $(5,9)$ Cooper et al showed that skills in BLS, defibrillation and airway management decline significantly within 6 months of training. (16) Nevertheless, our study noted that dentists' self-estimation of diagnostic and therapeutic competences decline within three to five years after the last postgraduate BLS/ALS training course. This could imply that the participation rate of dentists at BLS/ALS training courses would be highest when actively invited every three to five years. Moreover, it demonstrates the importance of BLS/ALS training on a regular basis.

Only about $51 \%$ of responding dentists estimated that they are competent to correctly and efficiently perform CPR. Similarly, Müller showed that only $49 \%$ of dentists felt competent in providing BLS. (5) Selfestimation of competence may be biased because there is a tendency to respond in a desirable social manner. (17) Accordingly, the potential disparities between self-estimation and actual knowledge and skills should be taken into account. Nadel et al showed that self-estimation exceeds actual skills of providing ALS. (18)

Our data show that dental offices in Slovenia are insufficiently and non-uniformly furnished with equipment to manage medical emergencies. Only eleven of the responding dentists had access to all ten basic emergency devices recommended by Medical chamber of Slovenia. (19) Meanwhile, since hypoglycaemia was the second most predominant medical emergency, providing glucose meters in dental offices could be beneficial.

It is known that a thorough medical history can help to reduce the risk of medical emergencies. (10) We showed that among Slovenian dentists, a general medical history is taken and written down in the medical 
file far less frequently than acceptable, according to the literature. (8) The observation that younger dentists take and update the general medical history less frequently than their older colleagues is further worrisome. This problem could be addressed by using validated medical risk related history questionnaires as has been recommended by Abraham-Inpijn et al. (8)

\section{CONCLUSIONS}

Medical emergencies in dental practice are common. Although the majority of them are not life-threatening, dentists, as medical professionals, should command adequate knowledge and skills on how to diagnose and manage them effectively. Since the relative and absolute incidence and expected level of management of medical emergencies in dental offices are different than in general practice, it seems reasonable to adjust undergraduate and postgraduate curriculum of dental students to address these specific medical states and highlight the use of available equipment in dental offices. Dentists in Slovenia do not possess the minimal equipment recommended by Medical Chamber of Slovenia, so more rigorous regulation by the official regulatory authority seems to be justified. Similarly, proper postgraduate BLS/ALS training for dentists on a regular basis is crucial to achieving the desired skills in diagnosing and managing medical emergencies. Since postgraduate BLS/ALS training in Slovenia is completely voluntary, we suggest that it could be most effective if dentists are systematically and actively invited to participate in BLS/ALS courses every three to five years.

\section{REFERENCE}

1. Atherton GJ, McCaul JA, Williams SA. Medical emergencies in general dental practice in Great Britain. Part 2: drugs and equipment possessed by GDPs and used management of emergencies. Br Dent J 1999:186:125-30.

2. Broadbent JM, Thomson WM. The readiness of New Zealand general dental practitioners for medical emergencies. N Z Dent J 2001:97:82-6.

3. Arsati D, Montalli VA, Florio FM, Ramacciato JC, Cuhna FL, Cecanho R, et al. Brazilian dentists' attitudes about medical emergencies during dental treatment. J Dent Educ 2010:74(6):661-6.

4. Atherton GJ, McCaul JA, Williams SA. Medical emergencies in general dental practice in Great Britain. Part 1: Their prevalence over a 10-year period. Br Dent J 1999:186(2):72-9.

5. Müller AP, Hansel M, Stehr SN, Weber S, Koch T. A state-wide survey of medical emergency management in dental practices: incidence of emergencies and training experience. Emerg Med J 2008;25(5):296-300.

6. Gridler NM, Smith DG. Prevalence of emergency events in British dental practice and emergency management skills of British dentists. Resuscitation 1999:41:159-47.

7. Ribaric S. Presentation document, Uniform second-level masters's program: Dental medicine. [Online].: 2016 [cited 2017 August 27]. Available from: http://www.mf.uni-lj.si/media-library/2016/06/5e0be389dcedddc1407c3c397e1balbe.pdf.

8. Abraham-Inpijn L, Russell G, Abraham DA, Backman N, Baum E, Bullon-Fernandez P, et al. A patient-administered Medical Risk Related History questionnaire (EMRRH) for use in 10 European countries (multicenter trial). Oral Surg Oral Med Oral Pathol Oral Radiol Endod 2008:105(5):579-603.

9. Marks LAM, VanParys C, Coppens M, Herregods L. Awareness of dental practitioners to cope with a medical emergency: a survey in Belgium. Int Dent J 2013:63(6):312-6.

10. Greenwood M. Medical emergencies in dental practice. Dent Update 2009:36(4):202-11.

11. Cram P, Vijan S, Fendrick AM. Cost-effectiveness of automated external defibrillator deployment in selected public locations. J Gen Intern Med 2003:18(9):745-54.

12. Slapnik E, Šmid T, Silič K, Starman T, Guzej J. AED baza Slovenije. [Online].: 2016 [cited 2017 August 27]. Available from: http:// www.aed-baza.si/.

13. Link MS, Atkins DL, Passman RS, Halperin HR, Samson RA, White RD, et al. Part 6: electrical therapies: automated external defibrillators, defibrillation, cardioversion, and pacing: American Heart Association Guidelines for Cardiopulmonary Resuscitation and Emergency Cardiovascular Care. Circulation 2010:122(3):706-19.

14. Statement from The Resuscitation Council (UK). Medical emergencies and resuscitation - Standards. [Online].: 2013 [cited 2017 August 27]. Available from: https://www.resus.org.uk/quality-standards/primary-dental-care-quality-standards-for-cpr/.

15. Haas DA. Management of medical emergencies in the dental office: conditions in each country, the extent of treatment by the dentist. Anesth Prog 2006:53(1):20-4.

16. Cooper S, Johnston E, Priscott D. Immediate life support (ILS) training: impact in a primary care setting? Resuscitation 2007:72(1):929.

17. Krosnick JA. Survey research. Annu Rev Psychol 1999:50:537-67.

18. Nadel FM, Lavelle JM, Fein JA, Giardino AP, Decker JM, Durbin DR. Assessing pediatric senior residents' training in resuscitation: fund of knowledge, technical skills, and perception of confidence. Pediatr Emerg Care 2000:16(2):73-6.

19. Možina H. Zdravila in oprema za uporabo pri nujnih stanjih v zobozdravstveni ambulanti. In Fras Z, Košnik M, Živčec Kalan G, editors. Nujna medicinska stanja v zobozdravstveni ambulanti. Ljubljana: Zdravniška zbornica Slovenije, 2012:46-51. 